\title{
BUSINESS AGILITY - NEW TREND IN BUSINESS
}

\author{
Lenka SMOLÍKOVÁ* \\ Department of Informatics, Faculty of Business and management, Brno University of Technology, \\ Kolejní 2906/4, 612 00, Brno, Czech Republic \\ *E-mail: smolikova@fbm.vutbr.cz
}

\begin{abstract}
This paper focuses on a new trend in management - business agility. This term is brand new in the field of management, but agile practices are well known in project management, especially in the IT sector.

Purpose - the purpose of the paper is to clear the ify the relevance of a brand new topic - business agility. This purpose will be divided into six partial purposes.

Research methodology - the research methodology consists of literature reviews as the first step followed by hypothesis and questionnaire survey.

Findings - the findings and results derived from the research and reported at the end of the paper. The questionnaire survey is carried out to support or disprove the hypothesis. The most significant chapters are finding results and conclusion.

Practical implications - the practical implications can be found in the model of business agility transformation that can be used in business, the potential risk of business agility transformation and benefits related to business agility.

Research limitations - there is one research limitation and it is basically because there are not many companies that are agile in the Czech Republic and the term of business agility is new and it can influence a number of the filled questionnaire.

Originality/Value - the originality and value can be seen in the contribution of this paper: the model of implementation business agility into the company.
\end{abstract}

Keywords: business agility, agility, management, business leader, SCRUM, agile, transformation.

JEL Classification: M00.

Conference topic: Digitalization of Business Process: Trends, Challenges, Solutions.

\section{Introduction}

Globalization and the expansion of the interface have allowed many companies to enter the global market. This, however, for companies is an entry into a highly competitive, complex, ever-changing environment that requires the ability to react quickly and adapt to these changes. Especially for e-business, small and medium-sized businesses, this dynamic environment challenges the transformation of its existing strategies into more adaptable and flexible, precisely because of the ability to cope with unpredictable changes and to survive the unprecedented threats posed by the business environment (Šochová, 2014). Business Agility represents an organizational change that is capable of functioning regardless of the field in which the company operates. Business Agility is actually agility from the point of view of the organization as a whole, it is a change in the culture and functioning of the whole organization, its ability to adapt, regenerate, rapid change based on internal but above all external changes. This is not chaotic enterprise management. Agile firms, unlike many classical firms, have a very clearly defined direction. It works like a fleet of small ships that all sail for one goal but have autonomous management within their mission (Šochová, 2014). The company's management is much more dynamic than usual, the iteration of the enterprise, unlike the classic annual plans, shorter intervals (cycles).

The basis is self-organizing teams that bring innovations and development, but also a change in leadership.

This paper presents a complete definition of agility, business agility, agility leader built to form a combination of systematic literature review and experience gain from research within companies. The purpose of the paper is to clarify the relevance of a brand new topic - business agility. 
The purpose of this paper can be divided into:

- An extensive literature review of the topic business agility;

- Research among Czech companies - the research will try to analyze the situation on the Czech market;

- Creation of questionnaire and preparation of questions for interviews with managers from selected companies;

- Setting hypothesis;

- Evaluation of hypothesis based on research;

- Creating suggestions and recommendations for agile leaders and creating steps for the agile transformation process.

\section{Previous research}

\subsection{Agile definition}

Agile as a method was born in February of 2001 when a group of developers interested in lightweight development methodologies met to talk about their views regarding effective development of software. The developers understood the importance of a model in which every development cycle iteration would learn from the previous one. Hence, this new methodology was much more efficient, flexible and team-oriented than any previous model (Ambler \& Holitza, 2013)

One of the main differences in comparison to traditional approaches, in an agile environment, team roles tend to blur. Joining an agile team is a lot like working in a mini-startup. All the members do whatever it takes to make the project successful regardless of title or their role in the team. However, members still have their core competencies (Rasmusson, 2010).

The agile approaches welcome changing requirements and aim at satisfying customer needs via iterative development cycles and co-design with customers and users (Bouwman, Heikkila, J., Heikkila, M., Leopold, \& Haakek, 2018).

The agile approach considers people as unique individuals instead of replaceable resources and puts great emphasis on their interactions and collaboration instead of just their knowledge. Agile focuses on creating a small team with cross-functional units, that is preferably located in the same room. There is no method or process imposed on these teams. On the contrary, they are supposed to self-organize. These teams are trusted to get the workload done using approaches that they themselves think are best (Agile Marketing Manifesto).

In order to achieve the best results while creating a product, the agile approach focuses on including the customer in the whole process of development. The collaboration between the team and the customer means continual reprioritizing and maintaining an ever-changing backlog of features that are described in a concise format. Their documentation begins as soon as they are selected for immediate implementation by the team. Each feature is described in compliance with simplicity to achieve the best possible design. The functionality of these features is verified by the customer as soon as the implementation process is finished (Agile Marketing Manifesto).

One of the fundamentals of Agile approach is a focus on quality. This is crucial for creating successful products. One of the ways to ensure the quality is to use Test-Driven Development (TDD). Using TDD means writing test code before writing production code. Among other important tools, using code reviews done mostly as pair programming, Definition-of-Done checklists, iterative development as adapting code due to changes or new insights, and refactoring as continual improvement code, all help to achieve the best possible architectures for products. High-quality architectures are never defined up-front as far as an Agile approach is involved. They are allowed to form further during the development of the product. However, if there is a need for an early definition of the architecture, then it is done only in a basic form (Agile Marketing Manifesto).

Even though there are many useful tools described and promoted throughout the Agile literature, tools are not considered crucial contributors to successful products. Tools for daily builds, continuous integration and automated testing are the most preferred ones among experienced Agile teams (Agile Marketing Manifesto).

Since motivation is very important for Agile team members, there is a need for removing repetitiveness from daily tasks. This leads to the implementation of automation processes throughout the development. Many Agile teams thrive for supportive environments, such as open office layouts and tools such as big task boards and burn charts. To sum up, tools in the Agile context are supposed to strengthen motivation, communication, and collaboration in a team (Agile Marketing Manifesto).

\subsection{Scrum}

Accelerating time to market, increasing productivity, and responding to changes based on priorities are the objectives of the agile frameworks, according to the state of the agile survey. Scrum is an agile methodology, although it is most commonly used in software development, it can be applied to almost any project. The scrum process is suitable for projects with rapidly changing or highly emergent requirements (Ardakani, Hashemi, \& Razzazi, 2018). 
Development using Scrum begins with creating a product backlog. This prioritized list of features and other necessary capabilities is required for delivering a successful product. Following the product, backlog ensures that the team is always working on the most important and highly prioritized task (Rubin, 2012).

Typically, work is delivered in short, time-boxed iterations. Their length ranges from one week to a calendar month. The team is self-organized and cross-functional, executing tasks such as designing, building, and testing. Each iteration starts with planning a highly-prioritized version of the product backlog since the original product backlog workload is too large to be completed in a single iteration (Rubin, 2012).

At the end of the iteration, the team and stakeholders meet to review the finished work to alter both planned work and the way the team plans to do it. In case any additional needed features appear, the product owner can create a new item for it and include the item in the product backlog, already ranked with corresponding priority (Rubin, 2012).

If appropriate, a shippable version of the product is released either at the end of each iteration or after a couple of iterations. Each iteration ends with the planning of the next one (Rubin, 2012).

The first breakthrough article describing the importance of empowered, self-organizing teams and outlining management's role in the development process is "The New New Product Development Game" (Takeuchi \& Nonaka 1986) that appeared in the Harvard Business Review. The article describes how companies such as Honda, Canon, and FujiXerox delivered world-class results thanks to a scalable and team-based approach to all-at-once product development (Rubin, 2012).

Its important influence resulted in weaving various concepts together and giving rise to what today we call Scrum. The term Scrum is borrowed from the sport of rugby. It refers to a way of restarting a game after an accidental infringement or when a ball has gone out of play. The authors of the article use this term to relate to the product development process. They bring up the importance of the team acting as a unit while delivering the product, or metaphorically passing the ball back and forth while going to the distance as a unit. According to the authors, this approach is better suited to nowadays competitive requirements (Rubin, 2012).

In 1993, Jeff Sutherland and his team at Easel Corporation took the ideas from the 1986 article and combined it with the concepts from object-oriented development, empirical process control, iterative and incremental development, software process and productivity research, and complex adaptive systems, to create Scrum process (Rubin, 2012).

Since then, many Scrum-specific publications have been published by authors such as Ken Schwaber and Jeff Sutherland, including Agile Software Development with Scrum (Schwaber \& Beedle, 2001), Agile Project Management with Scrum (Schwaber, 2004), and The Scrum Guide (Schwaber \& Sutherland, 2011).

\subsection{Scrum Roles}

Development of software while using Scrum requires one or more Scrum teams, consisting of three Scrum roles: Scrum Master, product owner, and the development team. Even though there might be more roles included in the team, only these three are necessary (Myslín, 2016).

The Scrum team is cross-functional, which means that its team members have different functional expertise. It is also self-organizing/self-managing as the team manage their own workload, shift work among themselves based on need and best fit, and participate in team decision making (Highsmith, 2004). The team consequently has a high level of autonomy (Holtzhausen \& de Klerk, 2018).

\subsection{Product Owner}

The product owner is the crucial point of product leadership and the only authority responsible for deciding which features and functionality to build, as well as the order in which to build them. The product owner must maintain and communicate a clear vision of the Scrum team's goal to all the participants of the development. As such, he or she is responsible for the developed and maintained solution's overall success (Myslín, 2016).

Whether the focus is set on an external or internal product; the product owner is obliged to making sure that the most valuable work is always performed. In order to ensure that the team rapidly builds the correct and most desired solution, the product owner closely works with the Scrum Master and the development team (Rubin, 2012).

The core responsibilities of a product owner are managing economics, participating in planning, grooming the product backlog, defining acceptance criteria and verification of their fulfilling, collaboration with the development team, and the stakeholders (Rubin, 2012).

The product owner is a combination of several traditional roles that exist in non-Scrum teams, mainly: product manager, product marketer, project manager, business analyst, and acceptance tester (Myslín, 2016).

\subsection{Scrum Master}

The significance of the role of Scrum Master lies in helping everyone involved understand and embrace the Scrum values, principles, and practices. Scrum Master is a coach that provides leadership in helping the whole organization to develop an organization-specific Scrum approach. As such, Scrum Master helps the organization in a difficult period of adopting Scrum (Rubin, 2012). 
Another crucial responsibility of the Scrum Master lies in protecting the team from any interference coming from outside, as well as removing any impediments that might endanger the team productivity. He or she has no authority to express control over the team and is rather a leader than a manager which is present in the activities he or she is occupied with throughout the day in a Sprint (Image7). Typical Scrum activities consist of working on the product backlog grooming activities, such as writing and prioritizing new product backlog activities with the product owner (Myslín, 2016).

Scrum Master helps to remove barriers between the roles in the team, allowing the product owner to focus on driving the development directly. Even though Scrum Master is not able to solve the problems of team members, he or she always helps and guides them as they solve the problems themselves (Rubin, 2012).

While coaching a new product owner, the Scrum Master assists the product owner in understanding the role and its core responsibilities, maximizing business outcomes using Scrum, listening to any complaints or requests for change and then parsing them to actionable improvements for the team (Myslín, 2016).

Scrum Master is always looking for opportunities to make the team more effective. He or she is the process authority of the team, ensuring that the team adheres to the Scrum values, principles, and practices along with any team's special approach or adjustment to Scrum. In order to maximize the business value of using Scrum approach, there is a need for continuous improvement of processes throughout the development (Šochová, 2017).

\section{Business, strategic and organizational Agility}

Strategic agility is the practice of continuously adjusting and adapting strategic direction in core business in a flow of strategy praxis over time, as a function of strategic ambitions and changing circumstances (Moton, Stacey, \& Mohn, 2018).

Organizational agility is the ability to survive and prosper in a competitive environment by sensing and reacting to external changes rapidly and effectively (Zhou, Bi, Liu, Fang, \& Hua, 2018).

Business agility is the ability of an organization to sense changes internally and externally and respond accordingly to deliver value to its customers. Business agility is not a specific methodology or even a general framework. It is a description of how an organization operates through embodying a specific type of growth mindset that is very similar to the agile mindset often described by members of the agile software development community.

Business agility is important for any organization that faces uncertainty and rapid changes. Business Agility is the ability of an organization to:

- Adapt quickly to market changes - internally and externally;

- Respond rapidly and flexibly to customers' demands;

- Adapt and lead change in a productive and cost-effective way without compromising quality;

- Continuously be at a competitive advantage.

\subsection{Agile business}

An agile Business in an organization that embraces the agile philosophy and values at its core.

- Research questions and approach.

- What is agility and how is different from waterfall model?

- Can be business agility applied to every business?

Advantages of being agile:

- Customers' satisfaction by rapid, continuous delivery;

- People and interaction are emphasized rather than process and tools;

- Face-to-face conversation is the best form of communication;

- Regular adaptation to changing circumstances;

- Higher product quality;

- Increasing control of process and projects;

- Reduce risk.

\subsection{Methodology}

The first phase in this research was a literature review and Internet research. This literature research focused on agility, business agility, and business leader. The literature review provided the necessary input to paper. Following hypotheses are the results of studying and applications of available knowledge and experience.

Hypothesis 1: Agile approach is mostly used in the IT sector in the Czech Republic;

Hypothesis 2: Most of the companies are using SCRUM methodology in the Czech Republic;

Hypothesis 3: Term business agility is a brand new in the Czech Republic.

The questionnaire survey was selected as a research method to verify the above hypothesis. Companies had been addressed according to their field of specialization. The sample was based on Czech companies. Data were collected 
from 35 companies. For more detailed information there were three interviews made by top management of companies where agile principles were already implemented.

The tools measuring the situation about business agility on the Czech market are a survey and documentation what has been already proven in the field.

\subsection{Findings and results}

Data obtained from the survey were analyzed to validate the hypothesis and provide necessary support for the implementation of the business transformation.

These findings and results were created after interviews and discussions with managers of the companies from the Czech Republic and they were based on the author's experience from this field.

The case hypothesis was tested by asking the relevant questions to companies (managers) from the Czech Republic in quantitative research. Based on the results of both the research and documentation, the conclusion either confirm or reject the hypothesis.

According to research, these hypotheses are:

Hypothesis 1: Agile approach is mostly used in the IT sector in the Czech Republic. TRUE. 75\% of addressed companies mentioned that they use an agile approach just in the field of IT. One of the company stated that they tried to implemented agile technique into their marketing department but they were successful. One of the reason was that employees were not ready for an agile style of working. Top management of the company still wants to implement agile for all company and they want to go through an agile transformation.

Hypothesis 2: Most of the companies are using SCRUM methodology in the Czech Republic. TRUE. 92\% of companies are using the SCRUM methodology. 30\% of companies mentioned that they are combining SCRUM methodologies with other agile methodologies. $15 \%$ of companies said that they still use some traditional approach and they combined with SCRUM.

Hypothesis 3: Term business agility is a brand new in the Czech Republic. TRUE. Most of the companies in the Czech Republic are aware of this term but they do not know how to use it in business and they do not know how to do the agile transformation.

The basic foundations of agile business are:

- split the project into short intervals (SCRUM uses the term sprint);

- continuous interaction with the customer, gradual refinement and eventual adjustment of outputs;

- informality: personal interaction is preferred.

Recently, the term Business Agility has often been used outside the IT area. Agile methods have proven to work and we hear more and more about Agile outside of IT, business engagement, organization-level Agile. Organizations are looking for a way to access their business so they are flexible, effective and quick to respond to changes. Active business engagement, and agile strategic management of an organization, it is important for organizations to be able to survive effectively in the long run in an environment that is globally rapidly changing, turbulent and not as predictable as it used to be in the past.

Adaptability, flexibility, and balance are the three key elements of Business Agility. It is an organizational change that works regardless of the nature of the business where the organization operates. It is actually Agility from the point of view of the organization as a whole, is the change in the culture and functioning of the whole organization, its ability to adapt, regenerate, and change rapidly on the basis of internal but mainly external changes. Management becomes far more dynamic than we are used to in the annual plans, business iterations revolve in short cycles, self-organizing teams, of course, containing business, bringing innovation and evolution, but also a change of leadership.

Based on the findings and the research, recommendation for companies where agile principles were already implemented, it follows potential risks of agility transformation.

\subsection{Agility and agil leader}

Agile strategies are adaptive and responsive. Adaptive in the way they invite change instead of trying to control it. Responsive by listening to feedback and action on it quickly. In contrast to strategies that plan to do, agile is this that plan to re-plan. Agile is designed to implement quickly and then listen, reflect, and adjust to become more effective.

The agile leader should be aware of these four core principles:

- Ability to define a vision: is the engine of change and motivation. The vision is not necessarily linked to the product and business but should also be directed at the organization as such. What do we want to achieve, why, what will it bring to us at the organization level?

- Motivate the ability to motivate and add energy. It is a competence closely related to the vision. When you have a good vision, it motivates itself. Agile leadership builds much on internal motivation than an external one. 
- Get feedback:_Feedback plays an important role in the agile organization. The art of gaining system-level feedback as such is critical for leaders. It's not just about being able to give feedback but to be able to perceive it itself.

-Implement the change: to change things, people and their behavior, to support and consolidate the emerging culture. Agile leadership begins with a change of self, its thinking, values, and behavior, its style of work. Change how I influence the people around me, how I interact with them, how I can inspire them to become a team, and they all draw for one rope and become themselves, leaders. The third element is changed at the system level, the change of the whole organization and its culture.

\subsection{Business agility transformation}

The question that companies have to start with is:

- Where are we and why do we need to be agile? Understanding why we need to agile is crucial for all transformation process.

- If a company goes through an agile transformation, it will concern team composition, team roles and changes in the role of manager.

- In classical management is the ratio of hard skills verse. soft skills $70 \% / 30 \%$. In agile Leadership are ratio and $80 \%$ soft skills and 20 hard skills.

Companies that are considering going through agile transformation should follow this suggested process.

Agile transformation process includes:

- Organization scan: current state analysis - the first step is to perform an analysis of the current state.

- Organizational assessment: creating a target concept - based on identified weaknesses, a suitable methodology is chosen to eliminate shortcomings.

- Agile strategy - Why agile? Presentation of the target concept - submission of the proposed management concept.

Editing the target concept - incorporating comments, queries, and leadership requirements into the target concept.

Approval of the target concept - endorsement of the target concept by the top management

- Training core team: Choosing a team - it is necessary to choose the appropriate team to implement the pilot project.

- Training and Workshops - the selected team will be trained to have information and knowledge on the new approach. Workshops are useful in this case to test knowledge.

We must not forget that our suppliers should be prepared for our agile transformation otherwise I cannot work properly.

According to the research, companies that want to be successful with business transformation should have their priorities in:

- Satisfying customer;

- Welcoming change;

- Self-organizing teams;

- Understanding what agile all is about and we need to be agile?

Some organizations are not ready for an agile approach.

If organizations are considering agile transformation, they should first consider their current cultural situation in the company and readiness.

There are companies in the world that have an agile approach implemented and have gone through a successful agile transformation:

For example Google, Spotify, Netflix, Zappos. They are all world well - know companies and in their field very successful. One of the reason is that from very first begging they understood the importance to be able to react quickly to changes.

In the Czech Republic, we don't have any company that successfully went through business agility transformation. They companies preparing themselves to this transformation such as: for example, Kiwi, Česká spořitelna, Škoda, Moneta Money Bank.

The key to agile transformation is, above all, the right culture of society. For example, research has shown that a low age average in the society plays a key role in the agile transformation.

\subsection{The potential risk and benefits of transforming business agility into the company}

It is important to note that business agility transformation in to the companies is related to some risk:

- Insufficient knowledge when introducing a new methodology;

- Poor understanding of the change introduced; 
- Refusal to accept a new methodology by the top management of the company;

- Rejection of change by employees;

- Lack of finance to implement the change;

- Members of the department (team) will leave during the implementation;

- The introduction of the change will have a negative economic impact;

- An insufficient number of skilled workers for new roles (specialization);

- Overloading resources;

- The disaffection of the deal on sale under the new methodology;

- Customer's incoherence when working with a new methodology.

Benefits related to business agility:

- Communication;

- Self - organizing teams;

-Freedom;

- Feedback.

\section{Conclusions}

Business agility refers to the distinct capabilities that allow organizations to respond rapidly to changes in the internal and external environments, without losing momentum or vision. Adaptability, flexibility, and balance are three of the qualities essential to long-term business agility.

For most organizations, developing the capabilities that comprise business agility will require that their leaders re-shape their understanding of leadership and management, and develop the new skills needed to lead people and manage operations in our radically changing world. Many leaders of companies focus on making their business work efficiently and on delivering high-quality customer service. However, if they lead to rigidity and the exclusion of variation then they can undermine the key advantage that small businesses have over large businesses - agility.

This paper makes a relevant contribution to the current state of business agility theory. Firstly, it provides a complete definition of the agility, business agility and business leader - built from literature and research papers. Secondly, very interesting research among Czech companies was made. Data obtained from quantitative research from 35 companies and from three interviews with top managers from Czech companies were analyzed and used for evaluation of the hypothesis.

The main findings from research can be summarized:

- The agile approach is mostly used in the IT sector in the Czech Republic;

- Most of the companies are using SCRUM methodology in the Czech Republic;

- Term business agility is a brand new in the Czech Republic.

Additionally, the most significant contribution this paper are:

- Agile transformation process: where seven steps of agility transformation process were given. There is also a list of international companies that were successful with the implementation of business agility. One of the reasons for their success is that from very first begging they understood the importance to be able to react quickly to changes;

- The potential risk of transformation business agility into the company and benefits related to business agility: there were analyzed 11 potential risks that can influence business agility transformation process;

- Benefits related to business agility: the reason why to go through all process of business agility transformation was given in this part of the paper.

All these parts can be used in practice for successful agility transformation.

Suggestions for future research can be:

- Obtain results from more Czech companies (approximately 100);

- Obtain and compare results from other countries from the similar market such as Poland, Germany, and Slovak, Hungary.

\section{Disclosure statement}

This paper has no competing financial, professional, or personal interests from other parties.

\section{References}

Agile Marketing Manifesto. (2018). Retrieved from http://www.agilemarketing.net/manifesto/

Ambler, S. W., \& Holitza, M. (2012). Compliments of IBM: Agile For Dummies. Hoboken: John Wiley \& Sons, Inc. 
Ardakani, M. R. M., Hashemi, S. M., \& Razzazi, M. (2018). Adapting the scrum methodology for establishing dynamic interorganizational collaboration. Journal of Organizational Change Management, 31(4), 852-866. https://doi.org/10.1108/JOCM-07-2016-0135

Bouwman, H., Heikkila, J., Heikkila, M., Leopold, C., \& Haakek, T. (2018). Achieving agility using business model stress testing. Electronic markets, 28(2), 149-162. https://doi.org/10.1007/s12525-016-0243-0

Highsmith, J. (2004). Agile project management: Creating innovative products (2nd ed.). Boston, MA: Addison Wesley.

Holtzhausen, H., \& de Klerk, J. J. (2018). Servant leadership and the Scrum team's effectiveness. Leadership and Organizational Development Journal, 39(7), 873-882. https://doi.org/10.1108/LODJ-05-2018-0193

Morton, J., Stacey, P., \& Mohn, M. (2018). Building and maintaining strategic agility: An agenda and framework for executive IT. California Management Review, 61(1), 94-113. https://doi.org/10.1177/0008125618790245

Myslín, J. (2016). Scrum: průvodce agilním vývojem softwaru. Brno: Computer Press.

Rasmusson, J. (2010). The agile samurai: how agile masters deliver great software. Raleigh, North Carolina: The Pragmatic Bookshelf.

Rubin, K., S. (2012). Essential Scrum: a practical guide to the most popular agile process. Upper Saddle River, NJ: AddisonWesley.

Schwaber, K. (2004). Agile project management with Scrum. Redmond, Wash: Microsoft Press. https://doi.org/10.1007/11499053_47

Schwaber, K., \& Beedle, M. (2002). Agile software development with Scrum. Upper Saddle River, NJ: Prentice Hall.

Schwaber, K., \& Sutherland, J. (2012) Software in 30 days. Hoboken: Wiley. https://doi.org/10.1002/9781119203278

Šochová, Z. (2017). The greatScrumMasterr: \#scrummasterway. Boston: Addison-Wesley. Addison-Wesley signature series.

Šochová, Z., \& Kunce, E. (2014). Agilni metody rízeni projekti̊. Brno: Computer Press.

Zhou, J., Bi, G., Lui, H., Fang, Y., \& Hua, Z. (2018). Understandingemployeee competence, operational IS alignment, and organizational agility - An ambidexterity perspective. Information and Management, 55(6), 695-708. https://doi.org/10.1016/j.im.2018.02.002 